UNDERGRADUATE RESEARCH IN NATURAL AND CLINICAL SCIENCE AND TECHNOLOGY (URNCST) JOURNAL Read more URNCST Journal articles and submit your own today at: https://www.urncst.com

\title{
2020-2021 IgNITE Medical Case Competition: Regenerative Medicine
}

Dejan Bojic, BScH Student [1]*, Bianka Bezuidenhout, BScH Student [1], Hertek Gill, BScH Student [2]

[1] Faculty of Medicine, University of Ottawa, Ottawa, Ontario, Canada K1N 6N5

[2] Faculty of Science, University of Ottawa, Ottawa, Ontario, Canada K1N 6N5

*Corresponding Author: admin@ignitecompetition.org

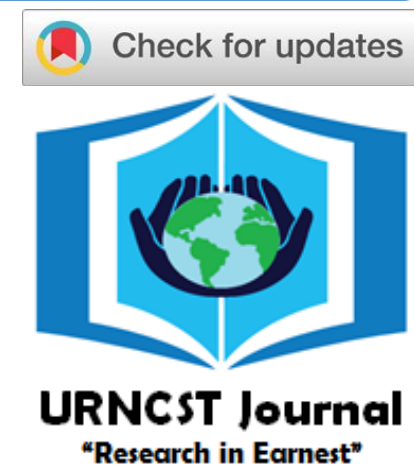

Note: Correction added after original version published on February 15, 2021. We regret any inconvenience caused.

\begin{abstract}
The IgNITE Medical Case Competition is an annual research case competition organized by students at the University of Ottawa. Our mission is to provide high school and university students the opportunity to gain valuable research experience while networking with industry professionals. Each year students, in teams of 1-4, are paired with an experienced mentor to develop and present a novel research proposal within the specified theme of the competition. During the competition, students are taught the fundamental principles underlying three lab techniques which they can then use in their proposal or their future research career. This year's theme was Regenerative Medicine and competitors learned about Immunofluorescence, Western Blot, and CRISPR-Cas9. In 2020-2021 the IgNITE community grew internationally with 570 high school and university students across the world participating in the competition. In this booklet we present the Top 40 teams and invite you to visit our website (www.ignitecompetition.org) to watch their pitch proposal videos. We hope you enjoy reading through some of this year's top proposals and invite you to join our growing community.
\end{abstract}

Keywords: IgNITE medical case competition; proposal; regenerative medicine; western blot; immunofluorescence; CRISPR-Cas9; undergraduate; high school

Table of Contents

IgNITE Medical Case Competition Abstracts

pg. A01-A17

\section{Conference Abstracts}

Note: These abstracts have been reproduced directly from the material supplied by the authors, without editorial alteration by the staff of the URNCST Journal. Insufficiencies of preparation, grammar, spelling, style, syntax, and usage are the authors.

\section{IgNITE Medical Case Competition Abstracts}

Injection of autologous mitochondria to regenerate osteoarthritic cartilage in rats Jeremy Azar [1], Yu Si Chen [1], Elizabeth Youjin Youn [1], Matthew Zhu [1]

[1] Faculté de médecine, Université de Montréal, Montréal, Québec, Canada H3T 1J4

In 2020, over 151 million people globally suffer from osteoarthritis (OA), the most prevalent cause of disability in older adults. Presently, no treatment can reverse OA cartilage damage. Current research suggests that mitochondrial dysfunction plays a key role in OA by decreasing extracellular adenosine levels, which dysregulates chondrocyte homeostasis. A recent study tackled this issue by injecting adenosine in OA rodent knees, which reversed cartilage damage by binding to the antiinflammatory receptor A2A. However, this method required weekly injections and did not fix the root of the issue. We propose mitochondrial autotransplantation in OA chondrocytes as a sustainable approach to increasing the production of ATP, which is then transported to the extracellular matrix and broken down into adenosine. It has already been demonstrated that mitochondria from bone marrow mesenchymal stem cells (BM-MSC) can be taken up by OA rat chondrocytes in vitro and that ischemic rabbit cardiomyocytes can integrate isolated mitochondria injected in vivo. We hypothesize that injection of mitochondria isolated from autologous BM-MSC into OA rat knees will result in increased extracellular adenosine, 
UNDERGRADUATE RESEARCH IN NATURAL AND CLINICAL SCIENCE AND TECHNOLOGY (URNCST) JOURNAL Read more URNCST Journal articles and submit your own today at: https://www.urncst.com

promoting cartilage regeneration. The isolated mitochondria will be tagged with LV-Mito-GFP4, an immunofluorescence marker, for later analysis. We expect a successful mitochondrial uptake that will ensure a steady and sufficient supply of extracellular adenosine, suggesting a long-term effect on regenerating OA cartilage. Treatment effectiveness will be measured through weekly comparison of OARSI scores, which assesses cartilage damage severity. If successful, mitochondrial transplantation could be further explored as a regenerative approach to treating osteoarthritis.

Cationic lipid NPs deliver CRISPR-Cas9 and replace the mutant dystrophin gene with microdystrophin Tala Salaheddin [1], Astha Chandra [1], Mawaia Elkbouli [1], Issraa Suliman [1] [1] Faculty of Medicine, University of Ottawa, Ottawa, Ontario, Canada K1N 6 N5

Duchenne muscular dystrophy (DMD) is a fatal genetic disorder causing progressive muscle degeneration due to lack of the dystrophin protein. There are around 1,111 mutations in the dystrophin gene known to cause DMD, making genetic editing more challenging. Current treatments use adeno-associated viral vectors (AAV) to transport a synthetic, abbreviated dystrophin gene - microdystrophin. However, this treatment lacks long term feasibility and cellular targeting, and can trigger a T-cell immune response. Unlike AAV transport, CRISPR-cas9 delivery through lipid nanoparticles avoids lysosomal degradation due to the surface cationic lipids. While gene insertions usually exploit homology-directed repair mechanisms, a new approach, homology-independent targeted insertion (HITI), makes use of non-homologous end joining. Cas9 cleaves the host and donor DNA and inserts the microdystrophin between the double stranded breaks. We intend to transfect mdx cells with cationic lipid nanoparticles containing the CRISPR-Cas9/sgRNA and the microdystrophin gene to utilize HITI to replace the dystrophin gene with the functional microdystrophin gene. This method will repair all possible DMD causing mutations within the genome, therefore offering a long-term solution. Western blotting for dystrophin protein concentration is expected to show increased levels of dystrophin. PCR followed by sequencing of the gene will then confirm correct gene replacement. Notably, lipid nanoparticles can be stored at moderate temperatures, and are less expensive than current DMD management protocols, making it accessible and cost-effective for shipment and storage worldwide. This methodology shows high therapeutic potential; however, future research should explore tissue specificity through in vivo intramuscular injections.

\section{Alzheimer's: Can astrocytic LRP1 rescue impaired hippocampal neurogenesis in rodents? Kyuree Kim [1] \\ [1] Thomas Jefferson High School for Science and Technology, Alexandria, VA, United States 22312}

Alzheimer's disease (AD), the most common form of dementia, is an age-related neurodegenerative disease characterized by progressive memory loss. One biomarker of $\mathrm{AD}$ is amyloid-beta $(\mathrm{A} \beta$ ) plaque deposition, which contributes to impaired hippocampal neuroregeneration. Previous studies revealed that low-density lipoprotein receptor-related protein 1 (LRP1) mediates A $\beta$ metabolism. Particularly, LRP1 in astrocytes plays an important role in hippocampal A $\beta$ clearance. Therefore, this study aims to investigate whether increasing astrocytic LRP1 (aLRP1) can rescue impaired adult hippocampal neurogenesis in AD mouse model brains. We will assess adult APP/PS1 amyloid mice models with varying aLRP1 levels (upregulated, removed, and control). An adenovirus will be used to transfect APP/PS1 mice with an LRP1 overexpression construct containing an astrocyte-specific promoter (GFAP). The effect of no aLRP1 will be examined using a previously established conditional knock-out of the LRP1 gene in astrocytes. We will then perform immunofluorescence to evaluate the number and distribution of $A \beta$ plaques (pan- $A \beta$ ), mature neurons $(\mathrm{NeuN})$, and neural precursor cells (Sox2). A BrdU assay will also be conducted to measure the number of proliferating Sox2-positive cells. Additionally, these mice will be assessed for memory retention using behavioral tests including the metric change task. Because aLRP1 has been shown to clear A $\beta$ plaques, we expect that increased aLRP1 levels will be correlated with increased hippocampal stem cell proliferation and neuronal differentiation as well as a better performance on the memory test. These results would suggest that increasing aLRP1 levels may represent a novel therapeutic strategy to rescue impaired neuroregeneration in AD.

Genetically enhanced regulatory $\mathbf{T}$ cells as a potential treatment for multiple sclerosis Aisha Bughrara [1], Fatma Legnain [2], Iman Yusuf Ali [3]

[1] Faculty of Social Sciences, University of Ottawa, Ottawa, Ontario, Canada, K1N 6N5

[2] Faculty of Dentistry, McGill University, Montreal, Quebec, Canada, H3A OG4

[3] Online High School, Independent Learning Center, Toronto, Ontario, Canada M4S 2B9

Bojic et al. | URNCST Journal (2021): Volume 5, Issue 2

DOI Link: https://doi.org/10.26685/urncst.241

Page A2 of A18 
UNDERGRADUATE RESEARCH IN NATURAL AND CLINICAL SCIENCE AND TECHNOLOGY (URNCST) JOURNAL Read more URNCST Journal articles and submit your own today at: https://www.urncst.com

Multiple sclerosis (MS) is a chronic autoimmune demyelinating neurodegenerative disease of the central nervous system (CNS) and the leading cause of disability in young and middle-aged people in the developed world. MS pathogenesis involves immune dysregulation mediated by myelin-reactive $\mathrm{T}$ cells, impairment of oligodendrocyte progenitor differentiation and limited function of regulatory $\mathrm{T}$ cells (Tregs). Tregs are well-known for their pivotal role in immuneregulation and self-tolerance, and they have been recently rediscovered for their ability to act as potent promoters of tissue regeneration including CNS remyelination via progenitor cell activation. Tregs' function depends on the continued expression of an essential transcription factor, ForkheadBoxP3 (FoxP3). Currently, MS treatment involves immunomodulation and symptomatic management but there is no cure. 2 We propose a novel treatment for MS, an adoptive transfer of mutant FoxP3+Tregs, where enhanced FoxP3 expression will allow these Tregs to fulfill their natural function of maintaining homeostasis and inducing regeneration and avoids conventional therapies' limitations and side effects. We will use CRISPR-Cas9 technology to incorporate FoxP3 gain-of-function mutation into CD4+ naive T cells and induce their expansion in an experimental autoimmune encephalitis (EAE) mouse model for MS. We expect to see an increased myelin distribution in CNS slices through histopathology and immunohistochemistry and an enhanced yield of CCN3 Tregs protein, an oligodendrocyte differentiation marker, on western blots when comparing treatment group with control. This novel Tregs cellular therapy can provide a promising and life-changing treatment for MS patients and revolutionize the therapeutic approach to autoimmune disease.

Using the dCAS9 activation system for the enhancement of IL-10 cytokine as a novel treatment for multiple sclerosis Jimin Lee [1], Maria Scarfo [1], Joanna Stanczyk [2]

[1] Faculty of Science, University of Waterloo, Waterloo, Ontario, Canada N2L 3G1

[2] Faculty of Arts and Science, Queen's University, Kingston, Ontario, Canada K7L 3N6

Canada has the highest rate of Multiple Sclerosis (MS) patients in the world and approximately 77000 Canadians are affected. In MS, myelin sheaths (oligodendrocytes) that insulate neuronal axons are incorrectly recognized as foreign material by autoreactive T-helper 17 cells (Th17). Th17 will communicate using interleukin proteins to recruit other immune cells for destruction. Interleukin-10 (IL-10), a unique cytokine mainly synthesized by monocytes and T cells, inhibits the activity of various immune cells, thus resulting in decreased inflammatory response. Presently, MS treatment is limited to short-term anti-inflammatory medications, and a fundamental treatment to cease or slow the demyelination has yet to be implemented. This study adopts the methodology from Meng et al used for myocardial infarction and applies it to MS. The dCas9 activation system (derived from the CRISPR-Cas9 system) will be produced using the dCas9-VP64-MS2 plasmid and the dSaCas9-VPR sequence to enhance the expression of the IL-10 gene in human cell lines (monocytes and T cells). The IL-10 protein level will be quantified and compared with immunofluorescence. We expect to see an increased production of IL-10, which will reduce the recruitment of other immune cells, thus slowing the damage to the oligodendrocytes. If successful, MS mouse models may then be used to test the correlation between IL-10 and the viability of oligodendrocytes. This novel method of using the dCas9 activation system in treating MS offers a potential treatment plan and increased longevity for MS patients.

The impacts of MUC2 gene deletion on the quantity of mucus production in cystic fibrosis using CRISPR-Cas9 Niyoosha Chowdhury [2], Maram El-Sharif [1], Jasnoor Gill [2]

[1] John McCrae Secondary School, Ottawa, Ontario, Canada K2J 4T2

[2] Colonel By Secondary School, Ottawa, Ontario, Canada K1J 7N4

CFTR protein (cystic fibrosis transmembrane conductance regulator) dysfunction is the primary cause of Cystic Fibrosis (CF). However, the role of the mucin proteins; a key component in mucus, remains unclear. Mucus overproduction inhibits the processes of various organs such as the motile cilia in the lungs and nutrient absorption of the digestive tract in $\mathrm{CF}$ patients. Mucin synthesis and secretion processes are potentially linked to mucus overproduction in CF. Among the discovered 21 mucins, MUC2 is a gel-forming mucin, found on chromosome 11, and is a potential link to mucus hypersecretion in the digestive tract and lungs. MUC2 contribution in mucus secretion is widely unknown, in both normal and hypersecretory states. As CF is characterized by mucus overproduction, it would be expected that there is an overexpression of all mucin proteins; however, the opposite has been observed in mucins MUC5B and MUC5AC. This investigation aims to look into the specific role of MUC2 in CF by using CRISPR-Cas9, to remove the DNA sequence coding for MUC2. This study will utilize a control mice group and a group with CF whose MUC2 gene will be removed using CRISPR-Cas9. Histological staining using extracted bronchiole and small intestine tissue samples will then undergo fluorescence microscopy to visualize levels of mucus and to compare between the wildtype and knockout mice groups. It is

Bojic et al. | URNCST Journal (2021): Volume 5, Issue 2

DOI Link: https://doi.org/10.26685/urncst.241

Page A3 of A18 
UNDERGRADUATE RESEARCH IN NATURAL AND CLINICAL SCIENCE AND TECHNOLOGY (URNCST) JOURNAL Read more URNCST Journal articles and submit your own today at: https://www.urncst.com

hypothesized that the removal of MUC2 via CRISPR-Cas9 has the potential to provide a novel underlying genetic mechanism to better understand Cystic Fibrosis.

Treating DMD by exon skipping with exo-AAV vectors

Aakansha Kanyal [1], Sam Turrigiano [1]

[1] BASIS Peoria, Peoria, AZ, United States 85383

Duchenne muscular dystrophy (DMD) is a x-linked genetic disease which affects 1 in 3500 males globally. DMD occurs when a mutation in the dystrophin gene shifts the reading frame of the sequence, causing a lack of dystrophin in the muscle fibers that leaves many immobilized by twelve. While there are no cures for this disease, there are several treatments which are used to offset the symptoms - among which is the use of an Adeno-Associated Virus (AAV) as a vector, expressing an antisense DNA sequence that forces exon skipping, resetting the reading frame and thus producing dystrophin. However, exon-skipping faces shortcomings as the AAV antibodies attack the vector, stunting transduction efficiency. Thus, we suggest the use of exosome-associated adeno-associated viruses (exo-AAVs), uniquely shaped particles found either within or on the surface of the exosome. We propose the use of an established method of producing high yields of exo-AAV to ensure delivery of the vector through the overexpression of CD9 in AAV. These vectors would contain antisense sequence coding for small nuclear RNA to target dystrophin exons. Then, the transduction efficiency would be checked through immunofluorescence. The expected results are that the use of exo-AAVs to deliver the sequence will increase the amount of muscle cells that express dystrophin and will continue expressing the protein for a longer period-exo-AAVs are able to bypass biological barriers easily and are resistant to neutralizing-AAV-antibodies. This study would fill in the shortcoming of current gene therapy by increasing the efficiency of the delivery system.

The application of clustered regularly interspaced short palindromic repeats-associated protein 9 (CRISPR/Cas9) for the treatment of stargardt's disease

Ibrahim Kettaneh [1], Suhaib Aldada [2], Seham Kettaneh [1]

[1] Kingston Collegiate and Vocational Institute, Kingston, Ontario, Canada K7L 3S7

[2] Mathematics \& Statistics, University of Toronto, Toronto, Ontario, Canada M5S 1A1

Stargardt's disease (STGD), also known as Stargardt's macular dystrophy or juvenile macular degeneration, is the most common form of inherited juvenile macular degeneration, leading to progressive loss of central vision. STGD is inherited as an autosomal recessive trait caused by mutations in the ATP-binding cassette, subfamily A, member 4 (ABCA4) gene which lead to accelerated accumulation of lipofuscin in the retinal pigment epithelium. It affects an estimated 925,000 persons worldwide, representing more than one-third of all inherited retinal disorders. Despite its high prevalence, STGD has no standard treatment at present. While gene replacement therapy using Adeno-Associated Virus (AAV) has emerged as a promising therapy for inherited retinal diseases, the $4.7 \mathrm{~kb}$ gene capacity of the AAV vector has hindered treatment of mutations in larger genes such as ABCA4. Therefore, in situ gene editing technology (CRISPR/Cas9) is needed to edit/correct only the mutated region of the gene inside the target cells. Several studies have successfully demonstrated the modification of disease-causing mutations and rescue of the pathological phenotype in animal models by delivering CRISPR/Cas9 via AAV. For the purpose of this study, we propose to develop a novel in vivo therapy to correct STGDassociated mutations (ABCA4) and demonstrate its efficacy in a STGD mouse model using CRISPR/Cas9 technology. Ultimately, this research study will explore the clinical potential of CRISPR/Cas9 technology as a new therapeutic approach for STGD and lay a solid foundation for the development of AAV and CRISPR/Cas9 combined treatment against any genetic ocular disease driven by a known pathogenic mutation.

Targeting IL-20R1 receptor to inhibit binding of cytokine IL-19 in mice with collagen-induced arthritis Alexandra Poulin [1], Rachel Klein [1], Stacey Katsafanas [1]

[1] Faculty of Science, McGill University, Montreal, Quebec, Canada H3A OG4

Rheumatoid arthritis (RA) is an autoimmune disease that affects one out of every 100 Canadian adults, with that number continuing to rise. RA attacks the joints, specifically synovial membranes, which become swollen and painful, impacting quality of life. Cytokines have been found to play an important role in the activation of immune cells attacking these joints. The IL-20R1 receptor binds three cytokines associated with RA, notably Interleukin-19 (IL-19), which is involved in regulation of synovial inflammation. Previous studies show that inhibiting IL-19 in patients with RA can significantly reduce 
UNDERGRADUATE RESEARCH IN NATURAL AND CLINICAL SCIENCE AND TECHNOLOGY (URNCST) JOURNAL Read more URNCST Journal articles and submit your own today at: https://www.urncst.com

inflammation and prevent further bone erosion. However, it is unknown if inhibiting its receptor will have these same effects. Thus, this study will assess the impacts of inhibiting the IL-20R1 receptor through the delivery of gene therapy in mice that have been introduced to collagen-induced arthritis (CIA), the experimental model of human RA. The IL-20R1 gene will be knocked out through CRISPR-Cas9, which will lead to the inactivation of the IL-20R1 protein and its binding site for IL-19. Progression of the disease will be monitored following treatment by observing mice paw thickness as well as by quantifying the level of bone erosion through real-time PCR. By inhibiting the IL-20R1 binding site, it is expected that this therapy will promote positive changes in CIA mice, including decreased inflammation (decrease in paw thickness) and the prevention of bone erosion. Ultimately, the inhibition of the IL-20R1 receptor can potentially lead to significant strides in rheumatoid arthritis treatment, improving the lives of thousands of patients with RA.

Increasing production of treg cells in order to suppress the autoimmune response in type 1 diabetes Aysha Abdul [1], Fatima Zulfiqar [1]

[1] Faculty of Science, Western University, London, Ontario, Canada N6A $3 K 7$

The prevalence of Type 1 diabetes (T1D) has increased 21\% between 2001 and 2009. T1D is an autoimmune condition that destroys beta cells responsible for making insulin. Current research focuses on transplantation of beta cells destroyed by the immune system. However, this remains ineffective due to the minimal survival of transplanted islet cells. Moreover, successful transplants require lifelong immunosuppression. Our study looks to increase regulatory $\mathrm{T}$ (Treg) cells, proven to decrease autoimmune response by suppressing autoreactive $\mathrm{T}$ cells beta cells. We look to increase Treg cells using two methods in an in vitro model. The first method involves increasing the production of Treg cells by enforcing the production of FoxP3; a nuclear transcription factor that determines the natural Treg development and function. By using homologydirected repair we would enforce the expression of FoxP3, consequently increasing production of Treg cells. The second method involves converting $\mathrm{T}$ conventional cells already present in the body into induced Treg cells (iTregs) using a growth factor. iTregs are then stabilized by depriving the CD28 signal and by stabilizing FoxP3 expression by CRISPR. These two methods are expected to increase the amount of Treg cells in the body thereby decreasing insulin destruction. The effectiveness of the treatment can be tracked by measuring the amount of Treg cells before and after treatment through live cell fluorescent imaging. If successful, further studies will be conducted on T1D mice models. increasing Treg cell production can be used to treat not only T1D but also other autoimmune diseases.

Cardiac muscle tissue regeneration to lessen long-term cardiovascular effects of COVID-19 through cytokine apoptosis Hannah Polley [1], Maria Puscas [2]

[1] Faculty of Science and Schulich School of Medicine \& Dentistry, University of Western Ontario, London, Ontario, Canada N6A $3 K 7$

[2] Faculty of Health Sciences, University of Western Ontario, London, Ontario, Canada N6A $3 K 7$

As information about the novel COVID-19 virus dominates the news, the detrimental long-term health consequences of the virus are overlooked. Prolonged elevated levels of cytokine interleukin-6 (IL-6), an immunoregulatory protein, contribute to chronic inflammation leading to myocardial cell death. This study aims to lessen the inflammation caused by cytokine proliferation (IL-6) and improve long-term cardiovascular prognosis of former COVID-19 patients. Blood from patients will be centrifuged and used to detect IL-6 levels using Western Blot. Elevated levels of cardiac troponin ( $>0.40 \mathrm{ng} / \mathrm{mL}$ ), associated with myocardial infarction, will be measured using immunofluorescence with troponin specific antibodies at the beginning of the study and again after treatment to test its effectiveness. Subjects with elevated IL-6 levels (>80 pg/mL) will receive pluripotent human mesenchymal stem cells (hMSCs) via intracoronary injections. As hMSCs can differentiate into cardiomyocytes, regeneration of heart tissue is expected to occur. To prevent future myocardial damage anti-IL-6 receptor monoclonal antibodies will be orally administered, binding soluble and membrane bound IL-6 receptors, preventing IL-6 binding. Simulated heart muscle tissue will be used, followed by animal models and clinical trials. We expect to see decreased inflammation in heart muscle and normal troponin levels $(0.00-0.40 \mathrm{ng} / \mathrm{mL})$, reflecting a lower risk of myocardial infarction. To counteract risk of poor cell retention and tissue regeneration failure, hMSCs will be delivered with injectable hydrogels to improve cell viability. This method will advance current cardiac regeneration treatments and control the negative cardiovascular effects related to cytokine levels, alleviating pressure on healthcare systems due to COVID-19. 
UNDERGRADUATE RESEARCH IN NATURAL AND CLINICAL SCIENCE AND TECHNOLOGY (URNCST) JOURNAL Read more URNCST Journal articles and submit your own today at: https://www.urncst.com

\author{
Reversing reduction of cortical thickness in schizophrenic patients using CRISPR-Cas 9 \\ Kenna Toohill [1], Amytis Saghafi [1] \\ [1] Handsworth Secondary School, North Vancouver, British Colombia, Canada V7R $1 Y 7$
}

Schizophrenia is a mental illness that can be identified as psychosis, meaning that it changes the patient's thinking, sense of self, and perceptions. This illness has a broad range of symptoms which have been observed clinically and biologically. As the psychotic symptoms of this illness progress, the rate at which cortical gray matter is reduced increases. This reduction occurs specifically in the right superior, middle frontal, and medial orbitofrontal cortical regions. While the connection between a reduction in gray matter and psychotic episodes can be made, there are no concrete studies presenting evidence on slowing or reversing the reduction. Research suggests microRNA-137 is involved in many symptoms of schizophrenia. As a result of these past studies, this experiment will determine whether microRNA-137 is more or less frequent in the brain of patients with schizophrenia. This can be done by performing a brain biopsy of NVHL rats, which display schizophrenia-like symptoms, then using immunofluorescence to identify genes containing microRNA-137 and finally using CRISPR-Cas 9 to either delete or duplicate the gene. We anticipate the changes regarding microRNA-137 will slow down the reduction of the cortical thickness in schizophrenic patients, specifically those who frequently experience fully progressed psychotic episodes. Overall, the use of this method could possibly alleviate and slow symptoms of schizophrenia, including: phonological memory, further psychological episodes, and language impairment. Additionally, this may be a major stepping stone in helping patients with many brain disorders who experience similar reductions in gray matter, such as bipolar disorder.

\title{
In-vitro functionalization and characterization of coaxial electrospinning poly-caprolactone scaffold for esophageal regeneration \\ Hanwen Wang [1], Jiahuan He [1], Xinyi Xie [1], Zhipeng Niu [1] \\ [1] Faculty of Science, McGill university, Montreal, Quebec, Canada H3A OG4
}

Esophageal disorders sometimes require replacement of the affected region, for which stricture and stenosis are the two major complications. Attempts have been made to construct acellular esophageal scaffolds to facilitate esophageal regeneration while preventing complications using different materials. Previous research using biodegradable poly-caprolactone (PCL) had unexpected fast degradation due to lack of protection from the esophagus' unsterile environment. For circumferential replacement applying different acellular scaffolds, the absence of appropriate muscular layers remains a significant challenge. Therefore, we proposed a strategy using coaxial electrospinning with PCL as core and collagen type I blended with growth factors as an outer shell to fabricate an esophageal scaffold. We will examine the enhancement effect of collagen outer shell and different growth factors, like laminin, insulin-like growth factor 1, epidermal growth factor 2, etc., in facilitating epithelium and smooth muscle layer formation by incorporating them separately into collagen to compare with the control PCL scaffolds (with and without the outer shell). Epithelization and smooth muscle layer formation are assessed in vitro by histological staining and immunofluorescence of scaffolds seeded with human esophageal epithelial cells and smooth muscle cells, respectively; degradation will be quantified by histological analysis; mechanical properties will be analyzed by uniaxial tensile test. We will obtain data for each growth factor in facilitating regeneration, and we anticipate the collagen outer shell to display protection and enhancement effect. If effective, this can serve as a potential alternative for esophageal replacement and provide valuable information to apply growth factors in other fields of tissue engineering.

\section{Combining menstrual blood-derived stem cells and remdesivir for severe COVID-19 treatment}

Andrew Cao [1], Daniel Jeyaraj [2], Henry Liu [2]

[1] Faculty of Science, University of Ottawa, Ottawa, Ontario, Canada, K1N 6N5

[2] Faculty of Health Sciences, Queen's University, Kingston, Ontario, Canada K7L 3N6

Remdesivir, a viral RNA-dependent RNA polymerase inhibitor by Gilead Sciences, has shown reductions in recovery time for coronavirus disease 2019 (COVID-19) patients, although its efficacy remains controversial. It has been proposed that combination approaches with immunomodulators may improve remdesivir efficacy. Mesenchymal stem cells (MSC) exert immunomodulatory properties that demonstrate potential in reversing COVID-19-induced pneumonia in early-phase trials. Menstrual blood-derived stem cells (MenSC) present a novel MSC-like source, superior in availability, proliferative ability, and ethicality than traditional sources. We aim to investigate the efficacy of MenSC-remdesivir combination therapy in reversing severe COVID-19-induced pneumonia. This randomized, double-blind, placebo-controlled study will recruit 40 participants, aged 18-39, with laboratory-confirmed severe COVID-19 pneumonia. Participants will be randomly assigned to either receive intravenous infusions of MenSCs (6,000,000 MenSCs per $\mathrm{kg}$ body weight on days 1, 3, 5, 7, and 9), remdesivir, combination treatment, or placebo. Menstrual blood samples will be collected from healthy females, aged 18-30, 
UNDERGRADUATE RESEARCH IN NATURAL AND CLINICAL SCIENCE AND TECHNOLOGY (URNCST) JOURNAL Read more URNCST Journal articles and submit your own today at: https://www.urncst.com

with informed consent, who undergo standard medical history and physical examinations. MenSC isolation and characterization follow previously-established methods. The primary outcome is the reversal of pneumonia, assessed through a patient's pulmonary sequential organ failure assessment (SOFA) score and pro-inflammatory blood cytokine concentrations of interleukin (IL)-6, IL-8, and tumor necrosis factor-alpha (TNF- $\alpha$ ), quantified using enzyme-linked immunosorbent assay (ELISA). We expect MenSC-remdesivir combination therapy to surpass remdesivir in inhibiting acute pulmonary inflammation. Investigating this promising combination approach is an essential step in improving outcomes of COVID-19 patients, along with providing insight into future therapeutic applications of MenSCs in other inflammatory diseases.

\section{The potential of CRISPR-Cas9 gene editing as a prevention strategy for alzheimer's disease Francisco Estrella Rodriguez [1], Jahnessa Velasquez [2] \\ [1] School of Health and Community Studies, Algonquin College, Ottawa, Ontario, Canada K2G 1V8 \\ [2] Faculty of Science, Carleton University, Ottawa, Ontario, Canada K1S 5B6}

Alzheimer's Disease (AD) is a progressive neurodegenerative disease most often known for memory impairment and cognitive decline that has led to Dementia. Dementia can affect a patient's behaviour, speech, visuospatial orientation and their motor system. The typical neuropathological footprints of AD are characterized by extracellular senile plaques composed of beta-amyloid and intracellular lesions of truncated and hyperphosphorylated tau leading to tangles. Alzheimer's is one of the biggest medical and social challenges and there has been very little progress in treating it. As of now it is a disease that we cannot prevent, cure, or even slow down. Effective medication for AD is elusive and many gene-targeted clinical trials have failed to meet the expected efficiency standards. CRISPR-Cas9 is an emerging technology to correct anomalous genetic functions and is now widely applied to the study of AD. CRISPR-Cas9 has shown great potential for correcting the unwanted mutations in $\mathrm{AD}$-associated genes. The novel contribution of this present research proposal is to examine the potential use of CRISPR-Cas9 as a treatment option for Alzheimer's Disease. This would be done by targeting associated genes that cause early-onset AD such as amyloid- $\beta$ precursor protein (APP), presenilin-1 (PSEN1), and presenilin2 (PSEN2); as well as those that are of significant risk factors for late-onset AD such as the apolipoprotein E4 (APOE4) gene.

The effects of induced pluripotent stem cell-derived endothelial cells on diabetic wound healing in a murine model Aleena Ghafoor [1], Alex Sheikh [2], Eva Deligiannis [3], Saba Siddiqui [4]

[1] Department of Microbiology and Immunology, Schulich School of Medicine and Dentistry, Western University, London, Canada N6A $3 K 7$

[2] Medical Sciences 2, Faculty of Science, Western University, London, Ontario, Canada N6A $3 K 7$

[3] Neuroscience, Schulich School of Medicine and Dentistry, Western University, London, Ontario, Canada N6A 3 K7

[4] Interdisciplinary Medical Sciences, Schulich School of Medicine and Dentistry, Western University, London, Ontario, Canada N6A $3 K 7$

Currently over 463 million people suffer from diabetes mellitus worldwide and up to $25 \%$ of these patients suffer from the most common complication, diabetic foot ulcers (DFUs). Treatment of DFUs is presently limited to wound debridement and infection prevention, which fails to address the pathophysiology of impaired wound healing that leads to limb amputation in $24 \%$ of cases. Mesenchymal stem cell-based therapies for chronic wound healing have been extensively-studied, however, invasive harvesting techniques and limited potency make them difficult to apply clinically. As a result, there is an increasing interest in induced pluripotent stem cells (iPSCs) but the effects of iPSC-based therapies in diabetic chronic wounds remain mostly unknown. In this study, we test the ability of iPSC-derived endothelial cells (iPSC-ECs) to improve the chronic wound healing abilities of diabetic mice. In vitro differentiation of iPSC-ECs will be confirmed using direct immunofluorescence with anti-CD31 antibodies. Laser Doppler flowmetry will be conducted at the wound site to analyze blood flow during wound healing, followed by histological anti-CD31 staining to correlate blood flow with capillary density. Regeneration of the extracellular matrix (ECM) will be monitored by visualizing collagen deposition at the wound site via histological trichrome staining. This study is expected to reveal increased capillary density and collagen deposition around the wound, indicating increased angiogenesis and ECM regeneration, respectively. The findings of this study are expected to validate the use of iPSC-ECs as a novel therapy to promote wound healing in diabetics and improve the outcome of those suffering from DFUs. 
UNDERGRADUATE RESEARCH IN NATURAL AND CLINICAL SCIENCE AND TECHNOLOGY (URNCST) JOURNAL Read more URNCST Journal articles and submit your own today at: https://www.urncst.com

Myelin regeneration in the central nervous system of multiple sclerosis mouse model with oligodendrocyte progenitor cells generated from endogenous fibroblasts via CRISPRa

Alexis Arvanitis-Vigneault [1], Robert Demerjian [1], Unteni Tsobgny Ouoba [1], Rayan Ramdani [2]

[1] Faculty of Science, University of Ottawa, Ottawa, Ontario, Canada K1N 6N5

[2] Faculty of Medicine, University of Ottawa, Ottawa, Ontario, Canada K1N 6N5

The loss or degradation of myelin in the central nervous system (CNS) is caused by various neurological problems such as Pediatric leukodystrophies, cerebral palsy, white matter stroke and multiple sclerosis (MS). MS is one of the most common debilitating neurological disorders in young adults. It is characterised by the degradation of the myelin sheath covering the nerves of the CNS and the inability of the adult oligodendrocytes to replace it. A potential therapy is the use of oligodendrocyte progenitor cells (OPC). Oligodendrocytes, the cells that usually produce myelin and that are lost in demyelinating diseases, can be replaced via the transplantation of OPCs which can be used for combating the effects of diseases such as MS. In this project, we are aiming for myelin regeneration by producing oligodendrocyte progenitor cells derived from endogenous cells via the CRISPR-Cas9 gene activation of the Sox10, Nkx6.2 and Olig2 transcription factors. The cells will then be transplanted into the brain of toxin induced demyelinated mice which will serve as a multiple sclerosis model. The remyelination of the brain tissue will then be observed via immunofluorescence targeting myelin basic protein (MBP) a marker for mature myelinating oligodendrocytes. We expect to find a significant augmentation in the amount of MBP in mice treated with OPCs. In essence, OPCs generated via the CRISPRa gene activation system can be a potential treatment for not only multiple sclerosis, but also for a plethora of diseases linked to demyelination in the CNS.

The role of axer-204 in neuron regeneration for myelomeningocele

Adela Gottardi [1], Chelsea Klein [1]

[1] Faculty of Science, University of Ottawa, Ottawa, Ontario, Canada K1N 6N5

Although surgical interventions for spina bifida exist, patients with myelomeningocele still have paralysis below the level of the deformity and therefore better treatments are needed. Axonal regeneration in the central nervous system is partly inhibited by the signaling of Nogo-66 receptors (NgR1) when bound to myelin-associated inhibitors (MAI), such as Nogo-A. Tissue exposed to the protein AXER-204 has been proven to deactivate NgR1 signaling by blocking the MAI from binding to the receptor. This promotes axonal growth and mobility recovery from lesions in the corticospinal tracts of the study's subjects. This research aims to investigate if AXER-204 can inhibit MAI-NgR1 binding for spinal cord neuron regeneration and improve mobility in rats with myelomeningocele. Rats with induced myelomeningocele will be divided into a control and an experimental group. The experimental group will receive an intrathecal injection of AXER-204 at the site of deformation. Post-injection tissue extracts from each group will be subjected to primary and secondary antibodies for the colocalization of the Nogo-A and NgR1 proteins immunohistochemically. Nogo-A will be localized using mouse IgG1 anti-Nogo-A and goat anti-mouse IgG1 (AlexaFluor568). NgR1 will be localized using rabbit anti-NgR1 and goat anti-rabbit (AlexaFluor647). It is expected that the immunofluorescent images of the experimental group will demonstrate that Nogo-A and NgR1 have a decreased interaction compared to the control group. Paired with mobility tests, the data will indicate that AXER-240 blocks Nogo-A binding to NgR1. Understanding of axonal regeneration in myelomeningocele can provide potential treatment improvement for patients and enrich their quality of life.

A personalized medicine approach using base editors to target Glu342Lys in alpha-1 antitrypsin deficiency Salman Farooqui [1], Soumya Shastri [2], Vidish Ramchurrun [1]

[1] Faculty of Science, University of Ottawa, Ottawa, Ontario, Canada K1N 6N5

[2] Faculty of Health Sciences, University of Ottawa, Ottawa, Ontario, Canada K1N 6N5

Emphysema is a pulmonary condition resulting in restrictions of respiratory function due to damage of the alveoli. When inherited, emphysema is primarily caused by a deficiency in the protein alpha-1 antitrypsin (AAT) that is produced within the liver. AAT deficiency is a result of a Glu342Lys missense mutation within the SERPINA1 gene. Although a modernized approach using antisense oligonucleotide (ASO) inhibitors shows promise in preclinical models, ASO's require repeated treatments and are very costly. The intention of this study is to revert the mutation to the wild-type in order to permanently resume the function of AAT. A model of AAT deficiency can be acted upon with the use of a base editor, dCas9, a catalytically inactive variant of Cas9. In order to do this, a promoter taken from hepatocytes can be reintroduced into mice with the A-G base editor by the use of an adeno-associated virus (AAV). The cell-type specific expression of the base editor will be determined by western blot comparing hepatocytes and epithelial cells to ensure that only hepatocytes are targeted. Immunofluorescence will then be used to compare lung tissue between a treated mouse and a control mouse to identify

Bojic et al. | URNCST Journal (2021): Volume 5, Issue 2

DOI Link: https://doi.org/10.26685/urncst.241

Page A8 of A18 
UNDERGRADUATE RESEARCH IN NATURAL AND CLINICAL SCIENCE AND TECHNOLOGY (URNCST) JOURNAL Read more URNCST Journal articles and submit your own today at: https://www.urncst.com

whether the treatment restores AAT function, in turn resuming the protection of alveoli, allowing them time to regenerate. This novel personalized medicine approach would hold the potential to permanently restore AAT function after a single treatment which would benefit AAT patients while also opening doors to treat other similar genetic diseases.

\author{
Modifying CRISPR/Cas9 nucleases to correct autosomal dominant retinitis pigmentosa \\ Cynthia Sun [1], George Yin [1], Jean-Ren Wen [2], Sophie Luo [1] \\ [1] Faculty of Science, McGill University, Montréal, Quebec, Canada H3A 0G4 \\ [2] Faculty of Arts, McGill University, Montréal, Quebec, Canada H3A OG4
}

Autosomal dominant retinitis pigmentosa (adRP) is a genetic retinal disease that affects approximately one in 16,000 people. The symptoms of adRP progress from gradual peripheral vision loss to total blindness. The heterogeneity of adRP makes it possible to pinpoint the specific genes that cause the mutations, and we can utilize Clustered Regularly Interspaced Short Palindromic Repeats (CRISPR)/Cas9 to correct them. Previous studies have demonstrated the successful use of CRISPR/Cas9 with in-vivo adRP allele specific ablation in the presence of a protospacer adjacent motif (PAM) sequence following the mutated allele. Unfortunately, the widely used Streptococcus pyogenes Cas9 (SpCas9)'s PAM-recognition ability is a major limitation in current adRP-related CRISPR/Cas 9 maneuvers. The purpose of our current study is to improve the specificity of Cas9's PAM-recognition. The methods used to achieve this include (1) non-SpCas9 and (2) modified SpCas9. Experiments will be conducted on rat models. CRISPR/Cas9 with increased PAM specificity can target doublestranded breaks (DSBs) more precisely, broadening the range of mutations that can be successfully targeted. Promising nonSpCas9 sources, such as Staphylococcus aureus and Streptococcus thermophilus, have smaller and more efficient Cas9 orthologs, which have been associated with higher specificity. SpCas9 itself can also be modified through bacterial selectionbased directed evolution and better designed to recognize alternative PAM sequences. Improving PAM specificity marks a significant advance in CRISPR/Cas9's potential to treat adRP, leading towards future breakthroughs in the field of regenerative medicine.

Exploring the immunogenicity of bPh1-qPAS1, an optogenetic protein

Ola Elsharif [1], Areeba Imran [2], Alexa Kouroukis [1], Suleman Tariq [1]

[1] Faculty of Health Sciences, McMaster University, Hamilton, Ontario, Canada L8S 4L8

[2] School of Interdisciplinary Science, McMaster University, Hamilton, Ontario, Canada L8S 4L8

Optogenetics is an extremely promising field in genetic research that has been used to explore a variety of behavioural and physiological disorders. Optogenetic proteins are light-sensitive ion channels that allow researchers to control the activation and inhibition of targeted neurons. This neuromodulation technology has been utilized as an exploratory and therapeutic tool for diseases such as Parkinson's, chronic pain, vision and hearing loss. However, many of these experiments are focused on animal models, as optogenetics faces barriers before it can be expanded for use in humans. One of these barriers is the need for a protein sensitive to near-infrared light to reduce phototoxicity risk. Redchuk et al. created a modified protein system, bPh1-qPAS1, which is able to respond to near-infrared light, enabling 40-fold activation or inhibition of a neuron. Although this protein has strong potential for clinical use, another barrier is its potential immunogenicity. In order to address this issue, we will perform an in vitro cytokine release assay with human neuronal cells cultured with the bPh1-qPAS1 system. This assay will use a peripheral blood mononuclear cell format and test for common cytokines (IL-2, IL-6, IL-10, IFN $\gamma$ and $\mathrm{TNF} \alpha$ ). We expect to see a lower magnitude of cytokine release with bPh1-qPAS1 protein when comparing it to the results of previous optogenetic immunogenicity studies. This will provide a better understanding towards determining if concurrent immunosuppression is needed for the use of optogenetics in humans. We hope this provides a step forward towards harnessing the power of optogenetic therapy.

Acid doped liquid metal scaffold for peripheral nerve communication restoration and regeneration after neurotmesis Stefan Abi-Karam [1], Abdullah Afridi [2], Emily Pallack [3], Keer Zhang [4]

[1] School of Electrical and Computer Engineering, Georgia Institute of Technology, Atlanta, GA, United States 30332

[2] College of Liberal Arts and Sciences, Department of Chemistry, University of Florida, Gainesville, FL, United States 32611

[3] College of Agriculture and Life Sciences, Department of Microbiology and Cell Science, University of Florida,

Gainesville, FL, United States 32611

[4] Herbert Wertheim College of Engineering, J. Crayton Pruitt Department of Biomedical Engineering, University of Florida, Gainesville, FL, United States 32611

Bojic et al. | URNCST Journal (2021): Volume 5, Issue 2

DOI Link: https://doi.org/10.26685/urncst.241

Page A9 of A18 
UNDERGRADUATE RESEARCH IN NATURAL AND CLINICAL SCIENCE AND TECHNOLOGY (URNCST) JOURNAL Read more URNCST Journal articles and submit your own today at: https://www.urncst.com

Peripheral nerve injury (PNI) affects over 20 million Americans, generating more than $\$ 100$ billion in healthcare costs. The most severe PNI is neurotmesis, complete transection, resulting in loss of motor and sensory function. Efficient regeneration of nervous tissue is difficult, and current regenerative scaffolds do not immediately reinstate signal propagation. Hyaluronic acid-hydrogels are proven to enhance neurite outgrowth in vitro and sensory recovery in vivo, relative to autografts. The GaInSn liquid metal (LM) is hypothesized to propagate and sustain action potentials over transected nerves to prevent tissue degeneration. We propose a surgically implantable protein-fusion hyaluronic acid (PFHA) scaffold doped with known neuroregenerative and pro-vascularizing factors as well as GaInSn to restore nerve function. In combining PFHA and GaInSn LM, we expect immediate re-establishment of action potential propagation and long-term regrowth of the nervous and vascular architecture. To validate our hypothesis, we will develop a simulation model which relates physical parameters of nerve cells and our scaffold at various stages of nerve recovery to equivalent circuit models. Circuit simulations along with rat models with crush-induced PNI will be used to verify signal conduction for biological efficacy. Upon validation, human clinical assessments will proceed using accelerometer-coupled electromyography (EMG) along with signal processing to measure patient recovery, which translates to restored grip strength and sensation. The results will be confirmed with MR Neurograph. Ultimately, our novel nerve regeneration scaffold will allow for the immediate restoration of nerve signal conduction, promote nerve regeneration, and improve quality of life for patients with PNI.

Regenerating myelin in multiple sclerosis: Enhancing nerve growth factor delivery with liposomes Kha Nguyen [1], Prachi Ray [1], Harmy Thakar [2]

[1] Faculty of Arts and Science, University of Toronto, Toronto, Ontario, Canada M5S 1A1

[2] Faculty of Health Sciences, McMaster University, Hamilton, Ontario, Canada L8S 4L8

There is currently no cure for Multiple Sclerosis (MS), an autoimmune condition characterized by limited myelin sheath around nerve cells. Instead, treatments are used to manage the severity of inflammatory symptoms. Currently, hematopoietic stem cell therapy, the most prominent approach within regenerative medicine to combat MS, has limitations such as complications with intravenous (IV) administration of stem cells, increased risks of infections and challenges with finding compatible donors. Therefore, we propose an alternative regenerative approach using the nerve growth factor (NGF), which has been shown to promote myelination. However, exogenous growth factor administration has presented its own challenges such as in vivo instability and inability to cross the blood-brain barrier (BBB). We propose that by inserting the NGF into a liposomal delivery system, the limitations of administered growth factor will be alleviated. Using liposomes modified with poly-(ethylene glycol) and BBB-targeting ligands, the encapsulated NGF will then be administered through an IV injection into an Experimental Autoimmune Encephalomyelitis (EAE) mouse model, which mimics MS demyelination. Afterwards, the cerebral cortex is homogenized and a western blot will be done for myelin basic protein (MBP). We expect the level of MBP to be greater in the mouse that received encapsulated NGF compared to a control EAE mouse or one administered with free NGF, demonstrating that the myelin regenerated through our proposed methods. Ultimately, our interdisciplinary research idea tackles the challenge of MS treatment using regenerative medicine while also considering crucial pharmacokinetic aspects to improve research to clinical translation.

\section{Inhalation of lung spheroid cell-secretome and exosomes during early bleomycin-induced inflammation to treat} pulmonary fibrosis in mice Nathan Liu [1], Kevin Pan [1], Preya Patel [2], Kaylan Wang [3]

[1] Faculty of Medicine and Health Science, McGill University, Montreal, Quebec, Canada H3A OG4

[2] Schulich School of Medicine and Dentistry, Western University, London, Ontario, Canada N6A 3K7

[3] Faculty of Health Science, Western University, London, Ontario, Canada N6A 3K7

Pulmonary fibrosis (PF) is an interstitial lung disease characterized by progressive scarring of lung tissue. Beyond lung transplants and palliative care, there is currently no treatment for severe PF. Dinh et al. developed a reproducible protocol for the expansion of lung spheroid cells and showed that the post-inflammation inhalation of lung spheroid cell-secretome and exosomes (LSC-SEC/EXO) decreases bleomycin-induced fibrosis and promotes lung tissue regeneration in mouse models. However, it is unknown whether LSC-SEC/EXO inhalation at the onset of inflammation causes a more significant reduction in inflammation and subsequent fibrosis than post-inflammation administration. As such, our research will examine the relationship between the time of LSC-SEC/EXO inhalation on bleomycin-induced inflammation and PF in mouse models. We propose the administration of LSC-SEC/EXO at the onset of bleomycin-induced inflammation (1-day post-induction) in one mouse model cohort and post-inflammation (day 10) in another cohort. Ashcroft scores will be used to evaluate PF in lung tissue samples. We will assess total and differential cell count and $\mathrm{C}$ reactive protein levels in bronchoalveolar lavage fluid as inflammatory indices. Additionally, protein levels of profibrotic cytokines, TGF- $\beta 1$ and MCP-1, will be quantified 
UNDERGRADUATE RESEARCH IN NATURAL AND CLINICAL SCIENCE AND TECHNOLOGY (URNCST) JOURNAL Read more URNCST Journal articles and submit your own today at: https://www.urncst.com

using a Western blot analysis. We hypothesize that LSC-SEC/EXO inhalation during the early onset of bleomycin-induced pulmonary inflammation in a PF mouse model will reduce inflammation and decrease fibrotic outcome. Our study may reveal immunomodulating properties of LSC secretions that could inform the development of an early intervention treatment for lung inflammation that potentially attenuates PF pathogenesis.

Mesenchymal stem cell differentiation into chondrocytes to regenerate cartilage in rheumatoid arthritis Abigail Gillis [1], Genevieve Belanger [1], Jessry Santos [1], Maham Sajid [1] [1] Faculty of Health Sciences, University of Ottawa, Ottawa, Ontario, Canada K1N 6N5

Mesenchymal stem cells (MSCs) are a class of multipotent stem cells with various applications in regenerative medicinal issues such as cartilage regeneration and increased mobility in rheumatoid arthritis (RA) patients. MSCs are non-hematopoietic stem cells that differentiate into mesodermal cells. These MSCs can be stimulated to differentiate into chondrocytes through many proteins; two of which are hypoxia-inducible factors (HIFs) and transformable growth factor-beta one (TGF- $\beta 1$ ). The purpose of this study is to suggest a solution to improve RA through cartilage regeneration in mice using two critical proteins for chondrogenesis while decreasing hypertrophy to minimize the risk of apoptosis and ossification. Firstly, HIFs will be added to the cultured MSCs to drop oxygen concentration inhibiting hypertrophy. Subsequently, TGF- $\beta 1$ will be applied to stimulate chondrogenesis. In order to separate the differentiated chondrocytes from MSCs, fluorescence-activated cell sorting (FACS) will tag an antibody against cell surface protein proteoglycan 4 (PRG4) expressed by chondrocytes and not MSCs. Western blot analysis will examine for type 2 collagen and glycosaminoglycans in cartilage's extracellular matrix as PRG4 suppresses inflammation in the joint, thus indicating its functionality. The mature chondrocytes containing these proteins will be injected in mice using a CIA [12] RA model to test its efficacy. This study's expected results are to observe higher rates of chondrogenesis, thus promoting cartilage regeneration. If this solution increases healthy cartilage formation in mice with RA, this study could start testing on larger mammals and human clinical trials.

Assessing the effectiveness of gene therapy by overexpressing PDX-1 and NKX6.1 to treat type 1 diabetes Althea Kho [1], Hunaiza Arshad [2], Mohammad Yousaf Moosa [1], Nabeeha Aftab [1]

[1] Faculty of Science, York University, Toronto, Ontario, Canada, M3J 1P3

[2] Fleming School of Nursing, Trent University, Peterborough, Ontario, Canada K9L OG2

Type 1 diabetes is characterized by the elimination of insulin-producing islet beta cells in the pancreas, resulting in acute insulin deficit. Patients diagnosed with insulin-dependent diabetes administer 2-4 insulin injections daily to prevent hyperglycemia and downstream complications including retinopathy and ketoacidosis. The PDX1 gene along with the NKX6.1 gene are essential to beta cell development and maturation in the pancreas. Based on previous studies, PDX1 is downregulated in diabetics and higher NKX6.1 expression has been shown to induce high cell turnover. Therefore, we hypothesized that overexpression of both genes in the pancreas would lead to an increase in beta cell production. To test our hypothesis, a gutless adenovirus vector coupled with a helper plasmid known as PGLAd was used to overexpress PDX1 and NKX6.1 into the pancreas of autoimmune non-diabetic mice. A hemoglobin A1c (HBA1c), glucose tolerance test (GTT), and a pancreatic biopsy followed by beta-cell staining was done prior to the experiment in all samples and 4 weeks post-virus delivery in the experimental samples. The results of the HBA1c and GTT test indicated lower average blood glucose levels and no disturbances in glucose metabolism in experimental mice, post treatment. The biopsy showed an increased number of visible beta cells in the pancreatic tissue, confirming the production of functional islet beta cells. The results proved to be consistent with our hypothesis, thereby paving a new path of treatment and potential cure to type 1 diabetes.

\section{Using CRISPR-CAS9 to edit mutations in the NPC1 gene in mice with niemann-pick disease type C Hera Jamil [1], Sanjana Kapuria [2], Serena Lakhan [3] \\ [1] Faculty of Sciences, University of Toronto Scarborough, Toronto, Ontario, Canada MIC 1A4 \\ [2] Faculty of Health Sciences, Queen's University, Kingston, Ontario, Canada K7L 3N6 \\ [3] Faculty of Health Sciences, University of Ontario Institute of Technology, Oshawa, Ontario, Canada L1G 0C5}

Niemann-pick disease type C (NPC) is an autosomal recessive, neurodegenerative disease induced by mutations in the genes encoding the integral membrane proteins Niemann-Pick C1 (NPC1) and C2 (NPC2). It affects many children and adults, causing seizures and cognitive disabilities. Mutations in either NPC1 or NPC2 genes prevent fat transportation and cause the accumulation of cholesterol in peripheral tissues. Although treatments may reduce NPC symptoms, no cure exists. As such, 
UNDERGRADUATE RESEARCH IN NATURAL AND CLINICAL SCIENCE AND TECHNOLOGY (URNCST) JOURNAL Read more URNCST Journal articles and submit your own today at: https://www.urncst.com

this study investigates the use of CRISPR-CAS9 to alter mutated NPC1 and provide a possible cure. Fertile mice (Mus musculus) will be divided into an experimental and control group. A prion promoter will bind to the DNA in musculus gametes and a guide sequence will be added to CRISPR-CAS9, along with donor DNA from non-mutated musculus. This corrects the base sequences coding for the NPC1 mutated gene in the experimental group. Then, the gametes of two fertile musculus will be fused together. Fibroblasts formed from NPC patients are known to demonstrate the effects of mutations. Thus, to determine the extent of NPC and the amount of mutated proteins in an affected fibroblast cell, a Western blot will be conducted using anti-NPC1 antibodies. The Western blot is expected to show less mutated NPC1 genes in experimental musculus as they are corrected by CRISPR. Immunofluorescence microscopy will be used by adding a marker lysosomeassociated membrane protein in order to visualize the reduced cholesterol deposits in the treated fibroblasts. Therefore, biotechnology can be used to find potential treatments to Niemann-pick disease type C.

Combatting the inflammatory effects and decreasing the persistence of multidrug-resistant tuberculosis by using genetically-modified exosomes Oviya Ananthakrishnan [1], Kshitija Mundle [2], Elvira Shah [2]

[1] Faculty of Science, University of Western Ontario, London, Ontario, Canada N6A $3 K 7$

[2] Faculty of Health Sciences, University of Western Ontario, London, Ontario, Canada N6A $3 K 7$

Multidrug-resistant tuberculosis (MDR-TB) is a strain of Mycobacterium tuberculosis resistant to isoniazid and rifampin, the key drugs for traditional tuberculosis treatment, making it a major global health concern. Previous research with Mesenchymal stem cells (MSC) has shown promise in alleviating MDR-TB, however, does not address the intracellular bacteria persistence in infected macrophages. The intracellular bacteria can be targeted by the autophagy-promoting factors carried by genetically-modifying MSC-derived exosomes (MSC-EC). If these exosomes are inserted into macrophages of MDR-TB patients, then the intracellular M. tuberculosis persistence and resulting inflammation can be alleviated. Autophagy is an immune mechanism that controls the progression of M. tuberculosis. Oligonucleotides called antimiR inhibit miR125a in macrophages, thus, upregulating the UVRAG gene expression to promote autophagy. The CRISPR-CAS9 system inserts the antimiR sequence to the Endosomal Sorting Complexes Required for Transport (ESCRT) region in MSCs, resulting in its expression in the MSC-ECs. The genetically-engineered MSC-ECs are inserted into a multicellular lung model of chronic MDR-TB to promote autophagy and reduce inflammation. The inflammatory response measured via ELISA techniques, and intracellular bacteria quantified by flow cytometry will assess the efficacy of our technique compared to existing treatments. In the lung model treated with genetically-modified MSC-EC, rates of lower intracellular bacteria and inflammation would be observed compared to first-line treatments. The edited MSC-ES brings forth a regenerative alternative to current TB treatments, which often fail due to increased drug resistance.

\section{Assessing the tumorigenic properties of different replicative senescence rejuvenation methods of mesenchymal stem cells Jimin Lee [1], Madalina Patron [1] \\ [1] Faculty of Medicine and Health Sciences, McGill University, Montreal, Quebec, Canada H3A OG4}

Mesenchymal stem cells (MSCs) cells are of particular interest for treating age-related diseases as they pose a significantly lower risk of being rejected by the recipient. However, they are prone to becoming senescent pre in vivo transplantation and thus lose their potency. Furthermore, there are concerns that the high level of genetic manipulations implicated in the methods used to rejuvenate senescent MSCs may contribute to genomic instability and subsequently, increased tumorigenesis. This paper aims to compare the tumorigenicity of different methods used to rejuvenate senescence, meaning the process of slowing down the aging of MSCs. Replicative senescence levels of MSCs will be assessed by the number of cells staining positive for senescence-associated beta-galactosidase (SA-B-Gal) activity and proliferation rates. The MSCs will then be rejuvenated by three different methods: deriving MSCs from induced pluripotent stem cells (iMSCs)a,e, deriving p53 MSC knockouts (-/+) and culturing MSCs in poly(ethylene glycol) hydrogel matrices (E $\sim 1 \mathrm{kPa})$. These cells will be transplanted into mice and the results will be assessed both in vivo and in vitro. The tumorigenesis levels of these cultures will be measured by the expression levels of RAS, RB1, Nrf2 and VHL through western blot, as well as examining histological cell morphology and growth rate. We expect tumorigenic cells to have decreased NRF2, RB1 and VHL expression, and increased RAS expression. The preferred method will be the one with the highest senescence reversal potential and lowest tumorigenic properties.

Bojic et al. | URNCST Journal (2021): Volume 5, Issue 2

Page A12 of A18

DOI Link: https://doi.org/10.26685/urncst.241 
UNDERGRADUATE RESEARCH IN NATURAL AND CLINICAL SCIENCE AND TECHNOLOGY (URNCST) JOURNAL Read more URNCST Journal articles and submit your own today at: https://www.urncst.com

\author{
L’épigénétique au locus $\mathrm{A} 4 \mathrm{~V}$ pour ralentir la sclérose latérale amyotrophique familiale \\ Catherine Leclerc [1], Salma Bouziane [2] \\ [1] Faculté de Science, Université d'Ottawa, Ottawa, Ontario, Canada K1N 6N5 \\ [2] Faculté de Génie, Université d'Ottawa, Ottawa, Ontario, Canada K1N 6N5
}

La sclérose latérale amyotrophique (SLA) est une maladie neurodégénérative attaquant les neurones moteurs causant une paralysie musculaire mortelle. Les mutations dans le gène superoxyde dismutase 1 (SOD1) sont responsables pour $15 \%$ des cas de SLA familiale. L'origine de la maladie ne provient pas d'un problème dans l'activité enzymatique du gène, mais de la toxicité des défauts de repliement et des agrégats protéiques produits par une dérégulation cellulaire de la gestion du stress oxydatif dans les neurones. Par ce fait, la solution évidente serait de diminuer ces défauts pour ralentir la progression de SLA. Puisque les protéines de choc thermique (PTC) permettent le bon repliement des protéines, la suggestion serait d'augmenter leur expression en fusionnant l'histone acétyltransférase p300 et le facteur de transcription du choc thermique 1 (HSF1) au système CRISPR/dCas9 afin de les diriger au locus 7q12.3 des PTC. Les résultats attendus montreraient que dCas9-p300 activerait le gène en ajoutant des groupes acétyles à l'ADN, donc cela va relâcher la tension et permettre la transcription des PTC provoquée par HSF1. Le western blot sera utilisé pour confirmer l'augmentation des PTC suivi par l'immunofluorescence, afin de déterminer la réussite de l'expérience en révélant si les agrégats protéiques du gène SOD1 sont toujours présents. Si cela s'avère une réussite, le mécanisme constituerait une nouvelle source encourageante pour des futurs traitements en mesure de ralentir la progression et comprendre davantage cette maladie encore inconnue touchant environ 200000 personnes dans le monde.

\title{
Targeted expression of glycine-L-histidyl-L-lysine (GHK) to promote post stroke neurological regeneration
} Hanna Gibson [1]

[1] Faculty of Science, Carleton University, Ottawa, Ontario, Canada K1S 5B6

A stroke is a sudden interruption in the blood supply of the brain resulting in permanent tissue damage; causing weakness, paralysis, and coordination deficits. Close to 14000 Canadians die from stroke annually, with over 50000 new strokes a year - one stroke every 10 minutes. Glycine-L-histidyl-L-lysine (GHK) is a natural human tripeptide found in the blood plasma, saliva, and urine possessing a multitude of health positive biological actions; most notably anti-inflammatory capabilities. While GHK was shown to be successful in relieving neurological deficits and increasing the number of survival neurons in rat models post intracerebral hemorrhage, the intraperitoneal injection of GHK is quite invasive. Instead, I propose the expression of GHK within astrocytes via a targeted gene therapy to provide a less invasive, more effective solution to neurological regeneration post stroke. I will first use an adeno associated virus (AAV) to express His-tagged GHK (GHKHis) under the GFAP promoter to target the astrocytes which respond to stroke in a rat model via systemic injection. Astrocyte-specific expression will be verified by performing a co-immunofluorescence staining for His and for GFAP as well as performing a Western Blot test staining for His in both cerebral and muscle tissue. After confirming specificity of the AAV therapy, its effect stroke recovery will be tested by comparing rats injected with control viruses versus injection of the gene therapy AAV, through microscopy and behavioral analyses. If effective, this holds the potential to diminish the negative effects of strokes in patients.

Using oklahoma nitrone-007 and multivalent CAR-T cell therapy as a treatment for H3-K27M-mutant diffuse midline gliomas

Denise Cao [1], Rachel Beetham [1]

[1] Faculty of Science, Western University, London, Ontario, Canada N6A 3K7

Diffuse intrinsic pontine glioma (DIPG) is a H3-K27M-mutant diffuse midline glioma (DMG) which accounts for 75 to 80 percent of childhood brainstem tumours. Due to tumour location, DIPG is currently always fatal. Here, we propose to investigate a potential treatment to reduce the drawbacks of current methods through a combination of existing treatments for H3-K27M-mutant DMGs. We hypothesize that this novel combination of chimeric antigen receptor (CAR) T cell therapy and OKlahoma Nitrone-007 (OKN-007) treatment will be the most effective in ceasing tumour progression, preventing inflammation, and reducing cancer recurrence. To test this T-cells extracted from an orthotopic xenograft pediatric DIPG mouse model's own lymph will undergo CRISPR-Cas9 facilitated engineering to produce CAR-T cells targeting B7-H3 and GD2 antigens. Then, one group will undergo the combination treatment, the second will receive only CAR-T cells, the third will receive OKN-007 and unmodified lymph, and the last will be reinjected with unmodified lymph alone (control). These CAR-T cells will be administered ventricularly alongside OKN-007 administered orally. Treatment effectiveness will be determined through MRI for tumour progression, western blot for residual neoplasm analysis (e.g. p53), and ELISA for IFN-

Bojic et al. | URNCST Journal (2021): Volume 5, Issue 2

DOI Link: https://doi.org/10.26685/urncst.241

Page A13 of A18 
UNDERGRADUATE RESEARCH IN NATURAL AND CLINICAL SCIENCE AND TECHNOLOGY (URNCST) JOURNAL Read more URNCST Journal articles and submit your own today at: https://www.urncst.com

$\gamma$ proinflammatory cytokine levels. We expect that the combination method will have the most success, given that cytokine response syndrome, a severe side effect of CAR-T cell therapy, will be combatted with the proinflammatory-cytokine regulation properties of OKN-007. Altogether, the results from this study can improve the applicability and accessibility of CAR-T cells for previously terminal patients.

\author{
New murine model for multiple sclerosis based on T lymphocytes gene methylation changes: A tool for better \\ understanding the pathogenesis of the disease \\ Ines Ait Driss [1], Daniela Iachimov [1], Andreea Stepanov [1], Xiao Yu Xie [1] \\ [1] Faculty of Medicine, Université de Montréal, Montreal, Quebec, Canada H3T 1J4
}

With over 77000 cases, Canada presents one of the highest prevalence of Multiple Sclerosis (MS) in the world. The early onset of this incurable autoimmune disease engenders debilitating consequences, affecting the patient's quality of life. Although the precise causes of this inflammatory demyelinating affliction remain elusive, studies strongly suggest that environmental factors causing epigenetic changes contribute to the disease. It has been proposed that lymphocyte DNA methylation is an important factor in its pathogenesis. Unfortunately, the current models for MS are based on mice immunisation against Central nervous system (CNS) antigens and do not reflect accurately the etiology of the disease. In order to palliate the situation, this study proposes the creation of a chimeric murine model using an allograft of modified hematopoietic stem cells that recreate some of the methylation patterns seen in MS. The desired epigenetic modifications (hypermethylation of HLA-DRB1, DNHD1 and APC2 genes) will be achieved via the CRISPR-Cas12a system with a modified U-rich crRNA guide. After ensuring that hypermethylation and gene silencing was successful through immunofluorescence, the obtained phenotypes will be compared with controls by histopathology. In the new model, increased occurrence of nerve demyelination and infiltration of the CNS by T cells, myelin antigen-specific CD4+ T cells and MS specific cytokines is expected. If successful, this will be the first step in creating a new model that will not only allow for a better understanding of the origin of MS, but could also open the way for new treatments targeting those epigenetic modifications.

Use of lin28B-reprogrammed müller cells to mediate endogenous mitochondrial transfer in AMD Casey Qian [1], Zi Xuan Zhang [1]

[1] Faculty of Arts and Science, University of Toronto, Toronto, Ontario, Canada M5S 1A1

Atrophic age-related macular degeneration (AMD) is the progressive destruction of photoreceptor, retinal pigment epithelial (RPE), and Müller glial cells, leading to irreversible blindness. Currently, there are no FDA-approved treatments. Recent literature shows that dysfunctional RPE mitochondria underlies AMD pathogenesis, prompting a need to explore mitochondria-based therapies that intercept the disease at an earlier stage. We propose using Lin28B-dedifferentiated Müller cells (MCs) to transfer mitochondria through tunnel nanotubes (TNT) into RPE cells. Our goal is to replenish MCs and restore RPE mitochondrial health at early disease prognosis, and prevent further oxidative stress and retinal cell deterioration. We will use a GFP-labelled ShH10Y adeno-associated vector to transfect MCs with the Lin28B gene in Sod1-null mice modelling AMD. Lin28B encodes RNA-binding proteins that de-differentiate MCs into neural progenitors to adopt stem-like properties, and promote subsequent MC proliferation. TNT will mediate mitochondrial mobilization from the progenitors into the deteriorating RPE cells. We will evaluate mitochondrial health post-treatment by analyzing mitochondrial DNA copy number and damage, through qPCR. Mitochondrial structure will be observed using TMRE staining, and the level of ATP production will be evaluated using ATP assays. Finally, Western blots will be applied to quantify cell apoptosis markers (ex. Cleaved Caspase-3) relative to control levels. We expect to observe improved mitochondrial health and RPE survival in Sod1-null mice after treatment. This proposal presents a promising therapy for atrophic AMD in preventing RPE death and vision loss. Moreover, our research further elucidates the role of RPE cell mitochondria in AMD pathogenesis.

Presbyopia treatment by artificially synthesized alpha-crystallin insertion into lens

Judy Liu [1], May Jang [2]

[1] Biochemistry, Faculty of Science, McGill University, Montreal, Quebec, Canada H3A OG4

[2] Combined Major in Microbiology \& Immunology and Computer Science, University of British Columbia, Vancouver, British Columbia, V6T 124

One of the inevitable consequences we face as we age is decrease in functionality of our lens. Presbyopia is a condition which promotes progressive reduction in the eyes' ability to focus on nearby objects. This is due to continuous depletion of

Bojic et al. | URNCST Journal (2021): Volume 5, Issue 2

DOI Link: https://doi.org/10.26685/urncst.241

Page A14 of A18 
UNDERGRADUATE RESEARCH IN NATURAL AND CLINICAL SCIENCE AND TECHNOLOGY (URNCST) JOURNAL Read more URNCST Journal articles and submit your own today at: https://www.urncst.com

alpha-crystallin levels, a major lens protein, and is notably initiated around the age range of 45-60. This degradation is primarily caused by pyknosis, a condensation process in the proteins resulting from apoptosis. We propose an artificial increase in a-crystallin by direct application of a biosynthesised clone of the a-crystallin protein. Using Crispr-cas9, we can insert the genes encoding a-crystallin, CRYAA and CRYAB, into an expression vector. Then, we can transfer the vector into E. coli in order to clone the a-crystallin. To determine whether the protein is best introduced using injections, an oral pill, or eye drops, different mouse models will be established. By performing western blots and immunofluorescence, it is possible to quantitatively and qualitatively determine the most effective method of delivery while being able to exploit dosages and different compositions. Upon determining the most effective method of delivery as well as the optimal dosage to administer, it is possible to resolve lens aging and progression of Presbyopia. Presbyopia is a very common disorder and there are limits to how much we can prevent, as it is a natural process. Our solution could avoid the long-term side effects of current treatments including high-risk laser eye surgery and bifocal eyeglasses which could induce eye strain or dehydration.

Effects of collagen on relative strength of achilles tendon engineered tissue constructs Samuel Gobraeil [1], Thomas Habib [1]

[1] Bio-Medical Science, College of Biological Science, University of Guelph, Guelph, Ontario, Canada N1G 2 W1

Repair of Achilles tendon tissue (ATT) is often difficult, specifically in cases where the damage is irreparable surgically, due to its mechanical and load bearing requirements. Previous research has examined the use of tissue engineered constructs (TEC), left to soak in a collagen solution to strengthen the tissue. However, this method only restores 50-60\% of the load bearing capabilities. To improve recovery, we propose increasing the Platelet-Derived Growth Factor (PDGF) found in the TEC to augment collagen production. As a proof-of-concept CRISPR would be used to knock-in PDGF into TEC. Then, RTPCR would be performed to confirm an increase in the PDGF expression and western blot to confirm an increase in collagen production. Rats would be split into 2 groups, healthy ATT and rupture ATT, with each group being treated with Collagen enhanced TEC (TEC+) or untreated TEC. We will analyze whether the TEC+ treatment provides additional repair benefits over standard TEC and determine the relative strength compared to a healthy ATT. Applications of positive results would be diverse, allowing for improved strength in damaged ATT patients, restoring close to normal function and leading to enhanced quality of life. This is also greatly applicable to athletes where ATT injuries are common. Improved post-surgical strength would allow for quicker recovery and improved performance.

\section{PD-1/TIGIT dual downregulation and immunotherapy modified therapy for glioblastoma}

Maia Poon [1], Sarah Wong [2]

[1] Faculty of Science, McMaster University, Hamilton, Ontario, Canada L8S 4L8

[2] Faculty of Health Sciences, McMaster University, Hamilton, Ontario, Canada L8S 4L8

Glioblastoma (GBM) is the most common primary malignant brain cancer in adults. Despite aggressive chemoradiotherapy, GBM remains incurable, with a median survival of 15 months. While treatment modalities have been generated, including chimeric antigen receptor (CAR) T-cell therapy, a novel regenerative medicine strategy, clinical trials have been unsuccessful in GBM, likely due to immune checkpoint-mediated resistance. Immune checkpoints, under normal conditions, prevent destructive immune responses; however, in GBM, these checkpoints are overexpressed, leading to immune checkpointmediated CAR-T therapy resistance. As a result, currently, modified therapies involving blockades to inhibit GBM resistance of CAR-T cell therapy are being tested. Recently, CAR-T cells generated against lymphoma using patient-derived T cells combined with PD-1/TIGIT-downregulated CAR-Ts demonstrated antitumor effects in mouse xenograft models. We aim to apply this model to investigate how CAR-T knockdown of PD-1/TIGIT affects the efficacy of cell-based immunotherapies against GBM. To downregulate the two checkpoint receptors, PD-1 and TIGIT, we will use a two-in-one lentiviral construct that will express the CAR receptor, and knockdown vectors targeting PD-1 and TIGIT. By engrafting these CAR-T cells into mouse models, we expect to determine whether this modified immunotherapy increases potency and persistence of CAR-T cells to maintain cytolytic and proliferative capacity upon repeated antigen exposure. Our results may demonstrate that this cell-intrinsic PD-1/TIGIT dual downregulation and immunotherapy strategy may prove effective in overcoming immune checkpoint-mediated resistance, thereby improving the efficacy of CD19-targeting CAR-T therapy. If effective, we hope to progress toward clinical trials using this modified therapy.

Bojic et al. | URNCST Journal (2021): Volume 5, Issue 2

DOI Link: https://doi.org/10.26685/urncst.241 
UNDERGRADUATE RESEARCH IN NATURAL AND CLINICAL SCIENCE AND TECHNOLOGY (URNCST) JOURNAL Read more URNCST Journal articles and submit your own today at: https://www.urncst.com

\author{
Limiting immunogenicity of diabetic retinopathy patient-derived iPSCs by knocking out MHC and overexpressing \\ CD47 \\ Marria Khalid [1], Sabiha Lakhi [1], Hawa Patel [1], Shaza Syed [1] \\ [1] Life Sciences, Faculty of Science, University of Waterloo, Waterloo, Ontario, Canada N2L 3G1
}

Diabetic retinopathy (DR), the most common complication of diabetes, is characterized by vision loss due to vascular endothelial cell damage of the retina. Current therapies minimize vision loss by administering glucocorticoid drugs, however, adverse complications can occur. Notably, induced pluripotent stem cell (iPSC) therapy has shown promise in the regeneration of the retina after damage. A limitation of using these cells includes the risk of immune-rejection4. It has been proven that knocking out major histocompatibility complex (MHC) proteins prevents a host immune response to non-native cells; however, its depletion introduces natural killer (NK) cell-mediated responses. Overexpression of cluster of differentiation 47 (CD47) inhibits the activity of NK cells. This project aims to create a universal DR patient-derived iPSC platform whose immunogenicity is limited through genetic alterations. Specifically, iPSCs were reprogrammed from DR patient-derived fibroblasts and CRISPR-Cas9 was used to knock out MHC and overexpress CD47. Alterations were validated through Sanger sequencing, Western Blot and Immunofluorescence (IF) analysis. DR patient-derived iPSCs were differentiated into endothelial cells to mimic the DR afflicted endothelial cells. These differentiated cells were then cocultured with NK cells and a cytotoxicity assay was performed. Specifically, a chromium-release assay was used by loading radioactive chromium into the genetically modified and unmodified endothelial cells and the chromium released by dying cells was monitored. Compared to the unmodified cells, we expect less NK-mediated cell death for the genetically altered endothelial cells. Effectively limiting the immunogenicity of the donor-derived iPSCs can establish a universal platform for future studies in DR therapy.

Optimizing MSCs transplantation for treatment of ischemic stroke using a nanofiber hydrogel scaffold Adario Chirgwin-Dasgupta [1], Bao Linh Pham [2], Samir Gouin [3], Yin Nan Huang [2]

[1] Medicine, Faculty of Medicine, McGill University, Montreal, Quebec, Canada H3A OG4

[2] Medicine, Faculty of Medicine, Université de Montreal, Montreal, Quebec, Canada H3T 1J4

[3] Neuroscience, Faculty of Science, McGill University, Montreal, Quebec, Canada H3A OG4

Stroke occurs in more than 60,000 Canadians every year and is the primary cause of physical disability. Current treatment strategies, such as reperfusion and neuroprotective agents, are only available to a minority of patients and have limited benefits. Recent clinical trials have identified stem cell therapy as a promising approach to promote neurorecovery. However, administration methods and molecular factors must be optimized in order to improve graft implantation, cell survival, and new synapse formation. Nanofiber-hydrogel scaffolds (NHS) have shown to improve cell survival and neurite alignment, possibly favoring synapse formation, but have yet to be tested in living stroke models. Our aim is to determine whether delivery of stem cells seeded onto a NHS can optimize graft implantation and synapse formation. GCaMP transgenic mice with induced middle cerebral artery occlusion will be used to assess the implantation of NHS seeded with iPSC-derived MSCs. Experimental groups will receive either MSCs alone or MSCs-NHS. MSC localization and functional integration will be evaluated with calcium imaging and motor function will be assessed using the neurological severity score at specific time points. Synapse formation will be assessed using SV2A PET in vivo and immunofluorescence ex vivo. MRI will quantify glial scarring and tumor formation at these time points. We expect significantly greater improvement of all parameters in the MSCs-NHS group, particularly, a correlation of fewer adverse effects with high localization accuracy. The development of an effective neuroregenerative therapy would be a major advance in the management of stroke patients who cannot undergo reperfusion therapy.

Utrophin upregulation via promoter replacement using CRISPR-Cas9 Gabriel Berberi [1], Jean-Pierre Abdallah [2]

[1] Major Microbiology and Immunology, Faculty of Science, McGill University, Montreal, Quebec, Canada H3A OG4 [2] Major Physiology, Faculty of Science, McGill University, Montreal, Quebec, Canada H3A 0G4

Duchenne Muscular Dystrophy (DMD) is a fatal genetic disease that predominantly affects males caused by different mutations of the DMD gene. Such mutations result in various dystrophin alterations which cause muscle loss, weakness, and eventually death due to cardio-respiratory failure. Upregulation of utrophin A (UA), a homologue of dystrophin, is a commonly investigated treatment for DMD. It focuses on increasing its promoter activity with the help of novel transcription factors after genetic manipulation or exogenously delivered proteins. Using a novel approach, we aim to upregulate UA in

Bojic et al. | URNCST Journal (2021): Volume 5, Issue 2

DOI Link: https://doi.org/10.26685/urncst.241

Page A16 of A18 
UNDERGRADUATE RESEARCH IN NATURAL AND CLINICAL SCIENCE AND TECHNOLOGY (URNCST) JOURNAL
Read more URNCST Journal articles and submit your own today at: $\underline{\text { https://www.urncst.com }}$

mdx mice by replacing the promoter of the UTRN gene, coding for UA, in muscle stem cells —or satellite cells—with that of the highly transcribed ACTB gene, encoding actin. CRISPR-Cas9 will excise and replace the original UTRN promoter in satellite cells with the ACTB promoter. After introducing the modified cells into mdx mice, immunofluorescence microscopy against UA and RT-qPCR of UA transcripts will be compared between mdx, treated-mdx and wild-type mice. Moreover, Creatine Kinase $(\mathrm{CK})$ release will be measured using a Creatine Kinase-SL kit as an indication of muscle degeneration. It is expected that a successful UA upregulation in treated-mdx mice muscle cells, would lead to a reduction in CK release when compared to untreated-mdx mice, indicating lower muscle degeneration. Therefore, we intend to contribute to the ongoing investigation of UA upregulation as a potential treatment for DMD by investigating the possibility of upregulating UA expression permanently to a level that sufficiently replaces dystrophin.

\section{Conflicts of Interest}

The authors have no conflicts of interest to declare.

\section{Authors' Contributions}

BB: Co-President and founder of the IgNITE Medical Case Competition, assisted authors with their submission, reviewed the abstract submissions and ensured that they adhered to correct formatting standards, and gave final approval of the version to be published.

DB: Co-President and founder of the IgNITE Medical Case Competition, assisted authors with their submission, reviewed the abstract submissions and that they adhered to correct formatting standards, drafted the conference abstract booklet, and gave final approval of the version to be published.

HG: VP Logistics for the IgNITE Medical Case Competition, drafted the conference abstract booklet, and gave final approval of the version to be published.

\section{Acknowledgements}

We want to acknowledge the entire IgNITE Medical Case Competition Executive Team for helping ensure that this year's competition was an absolute success. The team that helped make this competition possible includes: Gayashan Tennakoon and Sandra Bojic as Co-Founders and VP Development; Dr. Jean-Francois Couture as Public Officer and Faculty Advisor; Rishan Vaitheeswaran as Public Officer; James Huynh as VP Graphics Design; Malek Rahmani and Georges Khalaf as VP Communication; Michel Vezarov as a VP Media; Catalina Fernandez as VP Ambassadors; Alberto Fuentes as VP Internal; Dené Bezuidenhout as VP Marketing Relations; Saif Dababneh as VP Finance; Yudhvir Bhatti and Aditya Prashar as VP Sponsorship; and Jean-Louis Parmasad as VP Mentors. Lastly, we would like to thank our branch coordinates and student ambassadors who helped establish IgNITE branches across North America, the 74 dedicated mentors who guided teams throughout the competition, the 62 professors who judged competition proposals, and the 570 students who competed this year, all of you contributed to IgNITE's success and we hope to build on these accomplishments in the years to come.

\section{Funding}

Both monetary and non-monetary:

University of Ottawa Faculty of Medicine

Ontario Institute for Regenerative Medicine

Centre for Commercialization of Regenerative Medicine

Campus Vibez uOttawa

University of Ottawa Science Undergraduate Research Journal

Kaplan Test Prep

BeMo Academic Consulting

SOS Students Offering Support 


\section{Article Information}

Managing Editor: Jeremy Y. Ng

Article Dates: Received Jan 21 21; Published Feb 1521

\section{Citation}

Please cite this article as follows:

Bojic D, Bezuidenhout B, Gill H. 2020-2021 IgNITE Medical Case Competition: Regenerative medicine. URNCST Journal. $2021 \mathrm{Feb}$ 15: 5(2). https://urncst.com/index.php/urncst/article/view/241

DOI Link: https://doi.org/10.26685/urncst.241

\section{Copyright}

(c) Dejan Bojic, Bianka Bezuidenhout, Hertek Gill. (2021). Published first in the Undergraduate Research in Natural and Clinical Science and Technology (URNCST) Journal. This is an open access article distributed under the terms of the Creative Commons Attribution License (https://creativecommons.org/licenses/by/4.0/), which permits unrestricted use, distribution, and reproduction in any medium, provided the original work, first published in the Undergraduate Research in Natural and Clinical Science and Technology (URNCST) Journal, is properly cited. The complete bibliographic information, a link to the original publication on http://www.urncst.com, as well as this copyright and license information must be included.

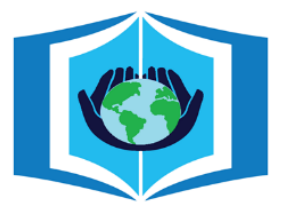

\section{URNCST Journal \\ "Research in Earnest"}

\section{Funded by the Government of Canada}

\section{Canadà̀}

Do you research in earnest? Submit your next undergraduate research article to the URNCST Journal!

| Open Access | Peer-Reviewed | Rapid Turnaround Time | International |

| Broad and Multidisciplinary | Indexed | Innovative | Social Media Promoted |

Pre-submission inquiries? Send us an email at info@ urncst.com | Facebook, Twitter and LinkedIn: @ URNCST

Submit YOUR manuscript today at https://www.urnest.com!
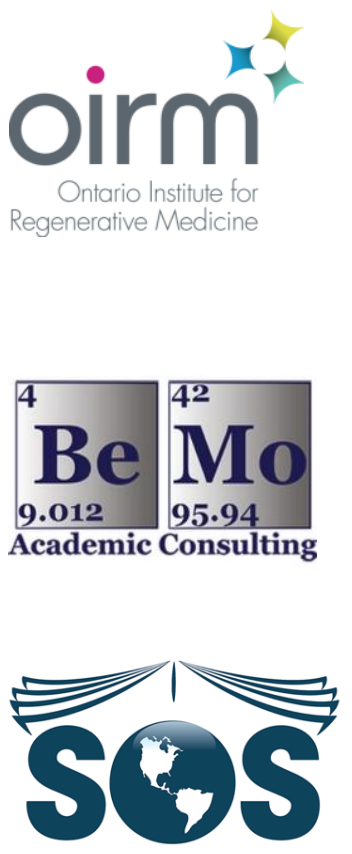
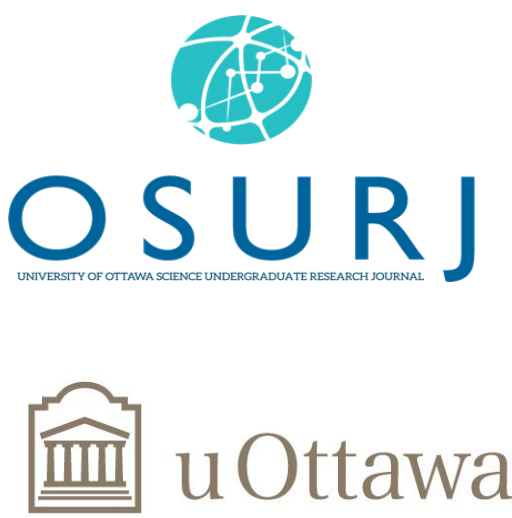

Faculté de médecine Faculty of Medicine

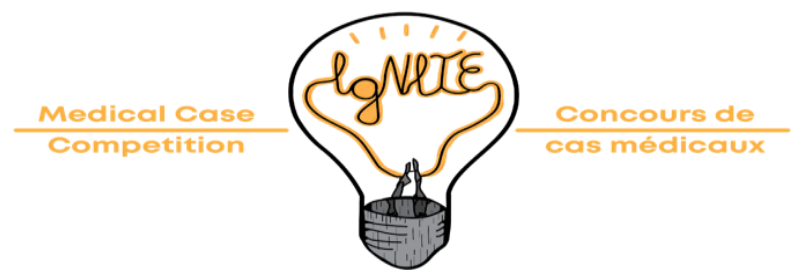

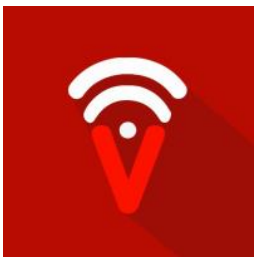

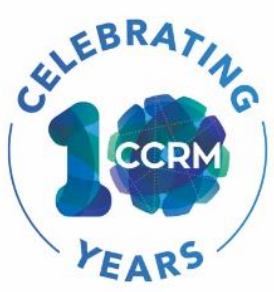

Page A18 of A18

Bojic et al. | URNCST Journal (2021): Volume 5, Issue 2

DOI Link: https://doi.org/10.26685/urncst.241 